\title{
Multivariate Analysis of Blood Pressure and Body Mass Index (BMI) for the Aged in Calabar South: The Counselors Intervention Strategy on Awareness Creation on Stress Related Disorder
}

\author{
Florence A. Undiyaundeye ${ }^{1}$, Effiom B. Ekeng ${ }^{1}$ and Godwin M. Ubi ${ }^{\star}$ \\ ${ }^{1}$ Department of Educational Guidance and Counseling, Faculty of Education, University of Calabar, \\ P.M.B 1115 Calabar, Nigeria. \\ ${ }^{2}$ Department of Genetics and Biotechnology, Faculty of Biological Sciences, University of Calabar, \\ P.M.B 1115 Calabar, Nigeria.
}

Authors' contributions

This work was carried out in collaboration among all authors. All authors read and approved the final manuscript.

Article Information

DOI: 10.9734/ARRB/2021/v36i830412 Editor(s):

(1) Dr Paola Angelini, University of Perugia, Italy. Reviewers:

(1) John Ogedengbe, University of Abuja, Nigeria. (2) Savita Hulamani, Karnataka State Akkamahadevi Women's university, India. Complete Peer review History: https://www.sdiarticle4.com/review-history/72215

Original Research Article

Received 24 May 2021 Accepted 03 August 2021 Published 13 August 2021

\begin{abstract}
Multivariate analytical study was carried out for the blood pressure (BP) indicators and body mass indices (BMI) for the aged in Calabar South Local Government area of Cross River State, Nigeria using the systolic, diastolic and pulse rate and for weight over the square of heights as indices for stress related disorders. The research focuses on multivariate analysis using principal component analysis, factor analysis, Cronbach's alpha statistics, biplot analysis, matrix plot, linear trend model and Turkey's multiple comparative statistics between age, blood pressure and body mass index among the aged of $60-90$ years. The study evaluated one hundred and twenty aged people separated into six groups based on age. Appropriate equipment and tools were used to measure the systolic and diastolic blood pressures and pulse rates. The body mass index was determined using weight over square of height $\left(\mathrm{kg} / \mathrm{m}^{2}\right)$. The data generated was analyzed using multivariate statistical analysis of Minitab v17 statistical software. The results revealed that all six age brackets evaluated
\end{abstract}


for the aged showed 66- 70 and $81-85$ yrs showed pre -obese conditions while the other four age brackets showed obese class 1 hypertension respectively. The results further showed that five principal components accounted for 100 percent of total variations in $\mathrm{BMI}$ and $\mathrm{BP}$ for the aged in the study area with principal component one (PC1) with eigen value of 0.398 contributing $56.90 \%$ to the observed total variation. The principal loading variable for this component was obtained from pulse rate (0.470). A trend linear model of $Y t=23.94+1.233 \times t$ was obtained for the trend analysis indicating the high dependence of the $\mathrm{BMI}$ and $\mathrm{BP}(\mathrm{Y})$ on age $(\mathrm{t})$. The results of Cronbach's alpha statistics revealed a high level of low precision and high standard errors among all variables evaluated showing less than 70 percent. The Turkey's multiple comparative analysis revealed high level of inconsistency among the variables as we compared one variable to another. The counselor's intervention strategy focuses on the creation of awareness on the need for a regular and routine blood pressure check - up for the aged, the need to create awareness on the potential risk factors that predisposes aged to increased blood pressure and pulse rates, the need for urgent guidance and counseling program for the aged on the dangers of drug abuse, smoking and poor dieting and the need for government safety nets intervention program for the aged to reduce increasing stress related disorders which is highly prevalence among the aged in the area.

Keywords: Stress related disorders; hypertension; breathing rate; principal components; loading values; trend model.

\section{INTRODUCTION}

Multivariate statistics is a subdivision of statistics encompassing the simultaneous observation and analysis of more than one variable like weight, height, systolic blood pressure, diastolic blood pressure, pulse rate and body mass index for the aged. Multivariate statistics concerns itself and help us to understand the different aims and background of each of the different aforementioned variables of multivariate analysis and how they relate to each other [1]. Multivariate analyses are widely employed in the evaluation and collection of statistical data to clarify and explain relationships between different variables such as the ones evaluated in the current study that are associated with targeted audience and parameters [2].

Blood Pressure (BP) is a measure of the force of blood flowing against the walls of the arteries. The blood pressure readings have two numbers which is indicated as $119 / 79 \mathrm{mmHg}$ for example and representing the Systolic/Diastolic or SYS/DIA measurement. Blood pressure is an index for determining stress related disorders in humans like hypertension and obesity [3].

Body mass index (BMI) is a simple index of weight - for - height that is commonly used to classify underweight, overweight and obesity in adults. It is defined as the weight in kilograms divided by the square of the height in meters $\left(\mathrm{kg} / \mathrm{m}^{2}\right)$. The BMI is also a very important indicator for measuring and determining stress related disorders in humans especially classes of hypertension and obesity status [4].
Stress related disorders are non-pathogenic diseases which are occasioned by increased blood pressure and abnormal body mass indices. These variables are quantitatively determined and hence the need to statistically analyzed them using the multivariate approaches. The high rate of dependency of increased stress related disorders makes the study of extreme importance [5].

Diseases are a lack of a healthy state of life, a disorder or illness caused by infections, genes defects and life style rather than by accident. Medically disease is defined as any deviation from or interruptions of the normal structure or function of any body part, organ or system that is manifested by a characteristic set of symptoms and signs and whose etiology, pathology and prognosis may be known or unknown [6]. Stress related disorders or disease is said to have caused over three hundreds million illnesses and over five million deaths against accident and other causes of death. For being the number one killer, conquering heart related diseases is given premium in the scale of preference of the quest to conquer nature in human search for reliable knowledge which is the immediate concern of scientific investigations [7]

The aged in the study area comprises of old people who are above the productive age brackets (18 - 59 years) in a developing economy as that of Nigeria [8]. They fall within the dependent age and as such are prone to severe discomfort, hardship, hunger and maltreatment [9]. Most people in this age 
brackets are retirees who passed through serious challenges to get their pensions and gratuity for their upkeep [10]. This ugly scenario is the major cause of the increased stress related disorders amongst the aged in the area [11]. It is against this backdrop, that this study was set up to statistically analyze the concern variables to enable for the drawing of meaningful conclusions and developing counseling strategies that can mainstream and reintegrate the aged into the society to enable the youths and government benefits for their wealth of experience and advice.

\section{MATERIALS AND METHODS}

\subsection{Research Area}

The study on the multivariate analysis of body mass index with incidence of hypertension and diabetes for the aged was carried out at Nsidung, Calabar South LGA, of Cross River State. The aged were the elderly people who were above 60 years of age in the study area.

\subsection{Study Population}

The study population consisted of 120 Aged respondents resident in Calabar South Local Government Area were studied. The Aged respondents were divided into six age brackets of twenty (2) each as follows;

(i) $61-65$ yrs designated as $\mathrm{A} 1$

(ii) $66-70$ yrs designated as $\mathrm{A} 2$

(iii) $71-75$ yrs designated as $A 3$

(iv) 76 - 80 yrs designated as A4

(v) $81-85$ yrs designated as A5

(vi) $\quad>86$ yrs designated as $A 6$

Twenty (20) aged respondents were randomly selected from each age brackets and used for the study. The respondents age was ascertained through questionnaire and birth related document. Both sexes of the respondents were used for the study.

\subsection{Blood Pressure}

Blood Pressure is a measure of the force of blood flowing against the walls of the arteries. The blood pressure readings have two numbers which is indicated as $120 / 80 \mathrm{mmHg}$ (Systolic/Diastolic or SYS/DIA). A single measurement of blood pressure does not provide an accurate indication of the true blood pressure. Hence the need to repeat measurements at specific time interval is ideal as done in the present study.

\subsection{Measurement of Systolic and Diastolic Blood Pressure}

The systole is the highest pressure in the cycle which is called the systolic blood pressure. This blood pressure is necessary to enable the evaluation of blood pressure status by healthcare professionals. The OMRON M2 Automatic Upper Arm Blood Pressure Monitor (Intellisense) for all health care was used in the determination of systole in $\mathrm{mmHg}$. It is a clinically validated intellisense technology which ensures accurate and comfortable measurement of content. Vietnam: Model (code): M2 (HEM-1721-E) with irregular heartbeat detection inbuilt meter. It ranges from $20-300 \mathrm{mmHg}$, with increasing risk of heart diseases as value increases. This measurement was repeated thrice at three days interval and the means taken for the different age brackets used in the study.

The diastole is the lowest pressure in the cycle which is called the diastolic blood pressure. This blood pressure is necessary to enable the evaluation of blood pressure status by healthcare professionals. The OMRON M2 Automatic Upper Arm Blood Pressure Monitor (Intellisense) for all health care was used in the determination of diastole in $\mathrm{mmHg}$. It is a clinically validated intellisense technology which ensures accurate and comfortable measurement of content. Vietnam: Model (code): M2 (HEM-1721-E) with irregular heartbeat detection inbuilt meter. It ranges from 1 - $150 \mathrm{mmHg}$, with increasing risk of heart diseases as value decreases. This measurement was repeated thrice at three days interval and the means taken for the different age brackets used in the study.

\subsection{Measurement of Pulse Rate}

This is the measurement of heart beats per minute. The OMRON M2 Automatic Upper Arm Blood Pressure Monitor (Intellisense) for all health care was used in the determination of diastole in $\mathrm{mmHg}$. It is a clinically validated intellisense technology which ensures accurate and comfortable measurement of content. Vietnam: Model (code): M2 (HEM-1721-E) with irregular heartbeat detection inbuilt meter. it displays 40 to 180 beats/min. This measurement was repeated thrice at three days interval and the means taken for the different age brackets used in the study. 


\subsection{Measurement of Weight $(\mathrm{kg})$}

The weights of ten (10) Aged respondents in the different age brackets were measured in kilograms using a manual weighing balance. Each respondent was made to climb the balance and the weight as displayed in the balance meter was recorded in kilogram and the average for each age bracket extrapolated and tabulated (Table 2).

\subsection{Measurement of Height (m)}

The heights of ten (10) Aged respondents in the different age brackets were measured in meters using a meter rule. Each respondent was made to stand beside the meter rule and the height was read perpendicular to the respondent head from the meter rule which was recorded in meters and the average for each age bracket extrapolated and tabulated (Table 2).

\subsection{Determination of Body Mass Index (BMI)}

Body mass index (BMI) is a simple index of weight - for - height that is commonly used to classify underweight, overweight and obesity in adults. It is defined as the weight in kilograms divided by the square of the height in meters $\left(\mathrm{kg} / \mathrm{m}^{2}\right)$. The mean weights and the heights measured from each of the respondents age brackets were used in the determination of the body mass index for each group. The BMI was tabulated in Table 2.

$\mathrm{BMI}=$ weight $(\mathrm{kg}) /$ Height $\times$ Height $\left(\mathrm{m}^{2}\right)$

Body mass index (BMI) is a simple index of weight - for - height that is commonly used to classify underweight, overweight and obesity in adults. It is defined as the weight in kilograms divided by the square of the height in meters $\left(\mathrm{kg} / \mathrm{m}^{2}\right)$.

\subsection{Data Analysis}

The data generated from the measurement of systoles, diastoles, pulse rates, weights, heights and calculation of body mass indices for all the age brackets. The Minitab V 17 statistical software was used to analyze for the correlation coefficients, regression analysis, comparative components analysis distribution of the identified parameters. The blood pressure chart was used to interpret blood pressure results for the different age brackets while the indicator Table 3 was used interpret the body mass index.

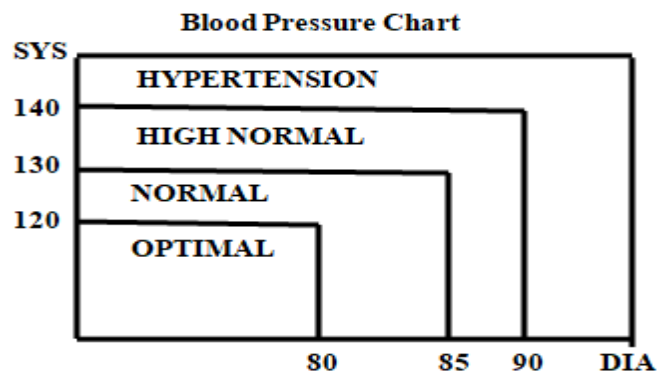

Fig. 1. Blood pressure chart

\section{RESULTS}

\subsection{Blood Pressure Indicators and Body Mass Index of the Aged in Calabar South}

The results of blood pressure indices including the systolic, diastolic and pulse rate and body mass index and its parameters measured and obtained from the aged respondents according to their age brackets are presented in Table 2. The results reveals that the youngest age bracket evaluated was 61 - 65 years while fisher folks between 96 years and above was the highest age bracket. The highest mean systolic blood pressure of $139 \mathrm{mmHg}$ was obtained from the 81 - 85 yrs age bracket and the least mean systolic blood pressure of $127 \mathrm{mmHg}$ was obtained from the $66-70$ yrs category. The highest mean diastolic blood pressure of $99 \mathrm{mmHg}$ was obtained from the 81 - 85 yrs age bracket and the least mean diastolic blood pressure of 64 $\mathrm{mmHg}$ was obtained from the greater than $86 \mathrm{yrs}$ category. The smallest mean Pulse rate of 59 heartbeats per minutes was obtained from the $>86$ yrs age bracket while mean of 79 heartbeats per minute was obtained from the $71-75 \mathrm{yrs}$ cadre respectively (Table 2 ).

Results of body mass index as presented in Table 2 revealed that only the age bracket of 61 $65 \mathrm{yrs}$ have a mean BMI of $31.39 \mathrm{~kg} / \mathrm{m}^{2}$ that falls within the obese class 1 range of health status (Table 2 and Fig. 1). The $66-70$ yrs and the 7175 age brackets showed mean BMI of 25.67 $\mathrm{kg} / \mathrm{m}^{2}$ and $30.51 \mathrm{~kg} / \mathrm{m}^{2}$ indicating pre-obese and obese class I health status conditions respectively. The $76-80,81-85$ and above 86 yrs categories showed BMI of $31.56 \mathrm{~kg} / \mathrm{m}^{2}, 27.42$ $\mathrm{kg} / \mathrm{m}^{2}$ and $30.46 \mathrm{~kg} / \mathrm{m}^{2}$ respectively revealing an 
obese Class 1, pre-obese and obese class 1 hypertension status (Table 2 and Fig. 1).

\subsection{Principal Component Analysis of Blood pressure indicators and Body Mass Index}

The results of principal component analysis of blood pressure indicators and body mass index of the aged in Calabar south is presented in Table 3. The results indicated that the systole, diastole, pulse rate, weight, height, age and body mass index (BMI) delineated the principal components into five (5) with all components contributing $100 \%$ to the total variations observed in the blood pressure indicators and body mass index of the aged in the study area. Principal component (PC1) one had the higher impact on the total observed variability contributing more than half $(56.90 \%)$ to the total variations. The eigen value for this component is 3.9846 with the major loading value of 0.470 coming from reduced pulse rate of the aged. Principal component (PC2) two showed an eigen value of 1.7449 and contributed only $24.90 \%$ to the observed total variations.

The principal loading value for this component of 0.565 was contributed by the weight of the aged. The eigen value for principal component (PC3) three is 1.1292 and a percentage contribution of $16.10 \%$ to the observed total variations among the aged (Table 3). The major loading value for this component is 0.528 and solely contributed by Body mass index (BMI). Principal component (PC4) four had an eigen value of 0.1290 with a contribution of $1.80 \%$ to the overall observed variations. The major loading value of 0.515 came from pulse rate of the aged. The last principal component (PC5) five showed an eigen value of 0.0123 with a small percentage contribution of $0.20 \%$ to the observed total variations. The principal loading value of 0.761 to this component was contributed by systolic blood pressure indicator for the aged (Table 3). The trend of the eigen values for the principal components are presented in Fig. 3.

\subsection{Biplot of Blood Pressure Indicators and Body Mass Index of the Aged in Calabar South}

The biplot of the blood pressure indicators and body mass index for the aged in the study area revealed that all the multivariate variables determined in the study were aligned in two major components as showed in Fig. 2. All the multivariate lies within the positive axis only above zero. The results indicated that all multivariate were positive for age, systole, diastole, BMI, weight, height and pulse rate. None lies on the negative axis of the biplot indicating significant variability among the indicators evaluated for the aged in the study area (Fig. 2).

The results of trend analysis plot for body mass index of the aged in Calabar South revealed a linear trend model of $\mathrm{Yt}=23.94+1.233 \times \mathrm{t}$. The trend revealed a linear model for body mass index $Y$ with age $t$. The results showed that the body mass index is actually dependent on the weight and height of the aged in the study area.

Table 1. Indications and classification of BMI $(\mathrm{kg} / \mathrm{m} 2)$

\begin{tabular}{|c|c|c|c|}
\hline $\mathrm{S} / \mathrm{N}$ & Classification & Principal-cut-off point & Additional cut-off points \\
\hline & Underweight & $<18.50$ & $<18.50$ \\
\hline & Severe thinness & $<16.00$ & $<16.00$ \\
\hline & Moderate thinness & $16.00-16.99$ & $16.00-16.99$ \\
\hline & Mild thinness & $17.00-18.49$ & $17.00-18.49$ \\
\hline & Normal Range & $18.50-24.99$ & $\begin{array}{l}18.50-22.99 \\
23.00-24.99\end{array}$ \\
\hline & Overweight & $>25.00$ & $>25.00$ \\
\hline & Pre-obese & $25.00-29.99$ & $\begin{array}{l}25.00-27.49 \\
27.50-29.99\end{array}$ \\
\hline & Obese & $>30.00$ & $>30.00$ \\
\hline & Obese Class I & $30.00-34.99$ & $\begin{array}{l}30.00-32.49 \\
32.50-34.99\end{array}$ \\
\hline & Obese Class II & $35.00-39.99$ & $\begin{array}{l}35.00-37.49 \\
37.50-39.99\end{array}$ \\
\hline & Obese Class III & $>40.00$ & $>40.00$ \\
\hline
\end{tabular}


Table 2. Results of average blood pressure measurements and body mass index determination for the Aged in Calabar south LGA of CRS

\begin{tabular}{|c|c|c|c|c|c|c|c|c|}
\hline $\mathbf{S} / \mathbf{N}$ & $\begin{array}{l}\text { Age bracket of respondents } \\
\text { (yrs) }\end{array}$ & $\begin{array}{l}\text { Systole } \\
\text { (mmHg) }\end{array}$ & $\begin{array}{l}\text { Diastole } \\
\text { (mmHg) }\end{array}$ & Pulse rate & Weight (kg) & Height (m) & $\begin{array}{l}\text { Body Mass Index } \\
\text { (BMI) } \mathrm{kg} / \mathrm{m}^{2}\end{array}$ & Remarks \\
\hline 1 & $61-65(\mathrm{~A} 1)$ & 132 & 92 & 73 & 82 & 1.63 & 31.39 & Obese Class I \\
\hline 2 & $66-70(\mathrm{~A} 2)$ & 127 & 88 & 69 & 76 & 1.72 & 25.67 & Pre-obese \\
\hline 3 & $71-75$ (A3) & 134 & 90 & 79 & 83 & 1.65 & 30.51 & Obese class I \\
\hline 4 & $76-80(\mathrm{~A} 4)$ & 137 & 89 & 71 & 89 & 1.68 & 31.56 & Obese Class I \\
\hline 5 & $81-85$ (A5) & 139 & 99 & 60 & 65 & 1.54 & 27.42 & Pre-obese \\
\hline 6 & $>86(\mathrm{~A} 6)$ & 136 & 64 & 59 & 53 & 1.32 & 30.46 & Obese class I \\
\hline
\end{tabular}

Table 3. Principal component analysis: BMI, systole, diastole, weight, height, pulse rate, age

\begin{tabular}{|c|c|c|c|c|c|c|}
\hline \multicolumn{2}{|c|}{ Eigenvalue } & 3.9846 & 1.7449 & 1.1291 & 0.1290 & 0.0123 \\
\hline \multicolumn{2}{|c|}{ Proportion } & 56.9 & 24.9 & 16.1 & 1.8 & 0.2 \\
\hline \multicolumn{2}{|c|}{ Cumulative } & 56.9 & 81.9 & 98.0 & 99.8 & 100 \\
\hline & Variable & PC1 & PC2 & PC3 & PC4 & PC5 \\
\hline 1 & BMI & -0.223 & 0.525 & 0.528 & 0.238 & 0.045 \\
\hline 2 & Systole & -0.432 & 0.267 & -0.325 & -0.222 & 0.761 \\
\hline 3 & Diastole & 0.147 & 0.452 & -0.681 & 0.504 & -0.215 \\
\hline 4 & Weight (kg) & 0.307 & 0.565 & 0.219 & -0.334 & -0.100 \\
\hline 5 & Height (m) & 0.459 & 0.242 & -0.149 & -0.511 & 0.026 \\
\hline 6 & Pulse rate & 0.470 & 0.013 & 0.267 & 0.515 & 0.509 \\
\hline 7 & Age & -0.465 & 0.268 & 0.102 & 0.047 & -0.321 \\
\hline
\end{tabular}




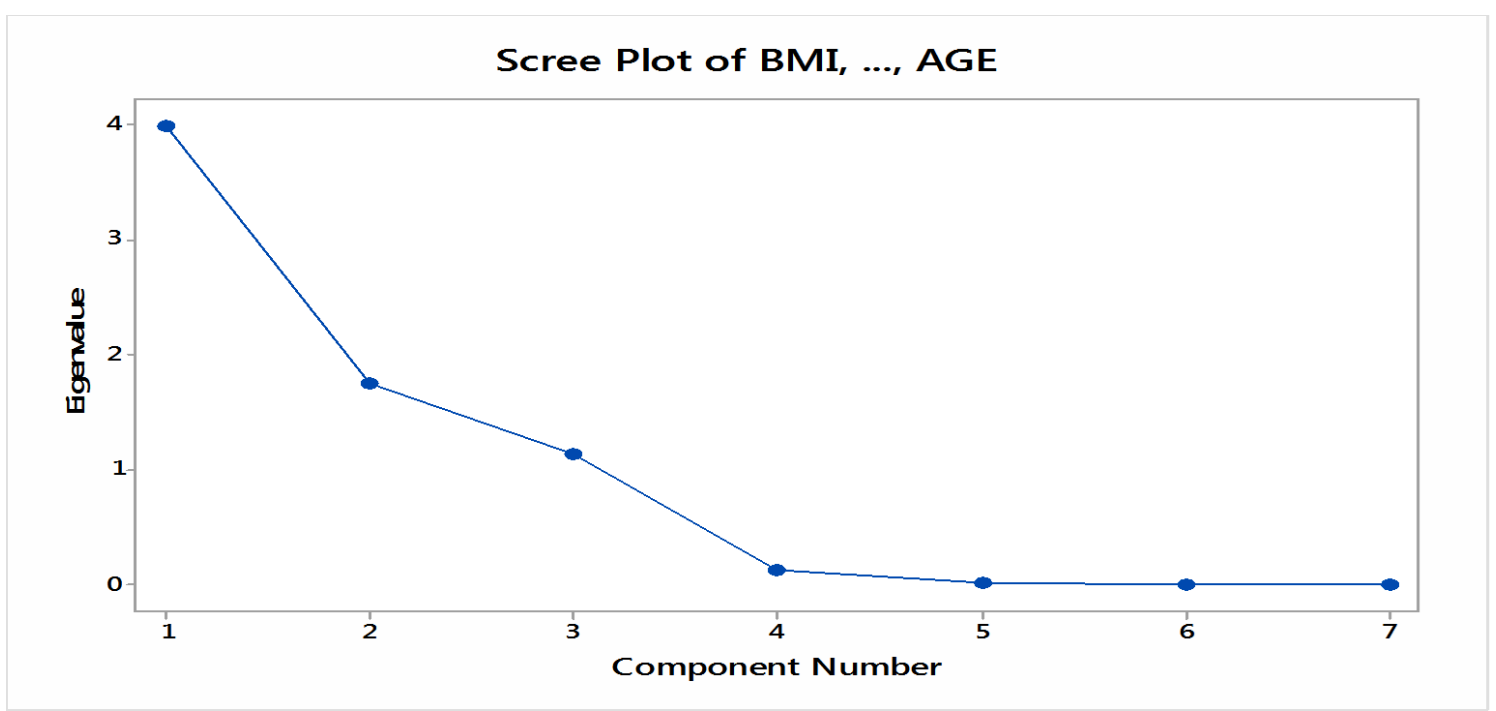

Fig. 2. Scree Plot of eigen values for Body mass index and blood pressure indicators against principal components

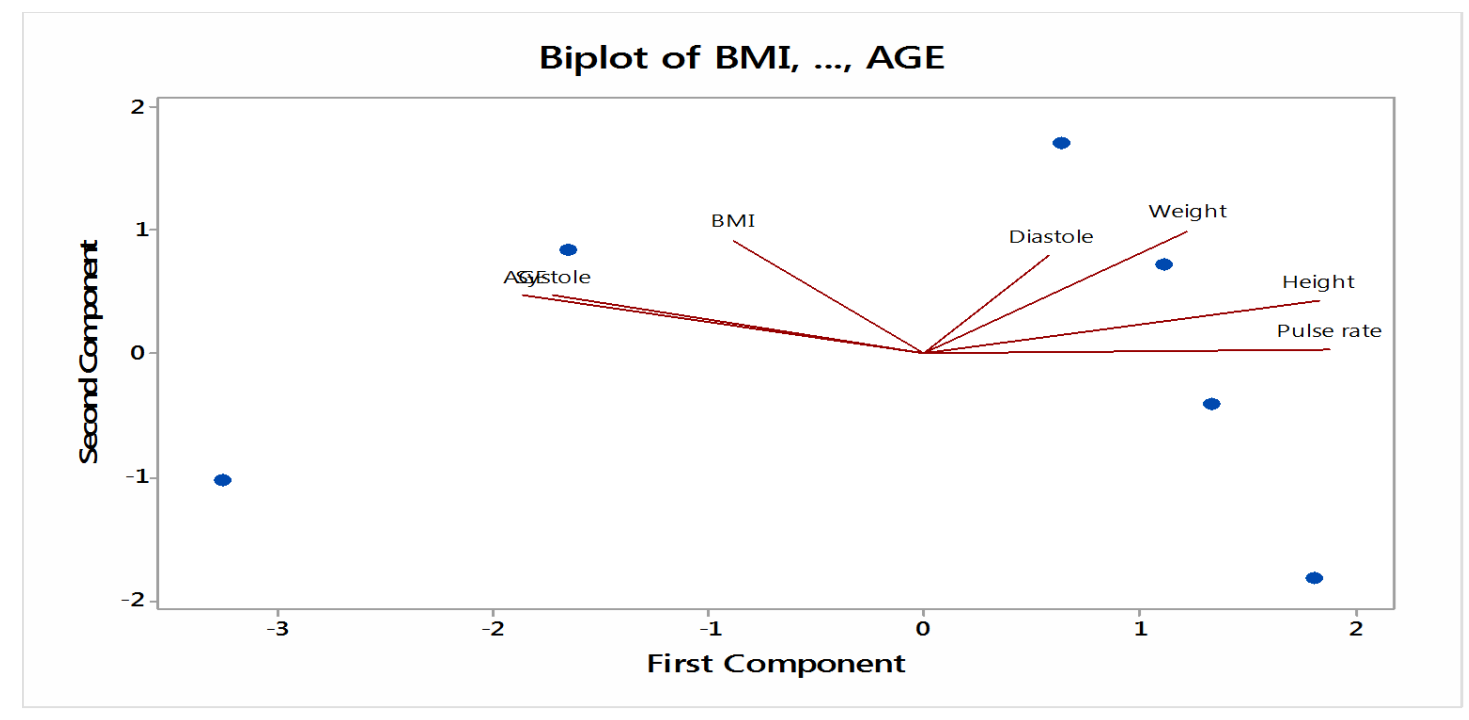

Fig. 3. Biplot of body mass index and blood pressure indicators with age

The results of item analysis for adjusted variables of body mass index and blood pressure indicators as presented in Table 5 revealed the highest adjusted total mean of $449.08 \mathrm{~m}$ of height was adjusted for the 81- 85 yrs aged people, while the least adjusted variable with total adjusted mean of $326.51 \mathrm{mmHg}$ systole was adjusted for the $66-70$ yrs aged people. The total adjusted standard deviation of $27.49 \mathrm{mmHg}$ for pulse rate was adjusted for aged people above 85 yrs old. The smallest standard deviation of $19.84 \mathrm{~kg}$ weight was adjusted for the $76-80$ yrs aged people in the study area. The total corrected variables were negative for systole, pulse rate and age assuming values of -
$0.1148,-0.1439$ and -0.1310 respectively. The results of Cronbach's Alpha for all the adjusted variables were an indication of bad measures as all variables had Cronbach values of less than 0.70. This further suggests a high level of inconsistencies of the internal variable after adjustment. The sets of measurement for the different variable indicators were widely apart without consistency a low degree of precision and accuracy.

Fig. 5 presents the results of matrix plots for body mass index, systole, diastole, weight, height, pulse rate and different age brackets for the aged. The results showed similar trends of 
BMI with pulse rate, height, weight and diastole. Similar trend of systole was observed with diastole, weight and height. Same observation and patterns of diastole was observed with weight and height. There were no similar trends in weight with other parameters as well as height and pulse rate.

The results in Table 3 represents the comparative study of the body mass index and blood pressures indices for the six different age brackets classified for the aged in the study area. The multivariate analysis reveals that there was significant $(p<0.05)$ differences in body mass index among age brackets $A 6$ and A5 age brackets of the aged studied. A similar result was obtained from the same age brackets $\mathrm{A} 5$ and $\mathrm{A} 6$ in the blood pressure test comparison which collaborated with the pairwise multiple comparisons in the BMI (Table 5)..

\section{Trend Analysis Plot for BMI}

Linear Trend Model

$\mathrm{Yt}=23.94+1233 \times \mathrm{t}$
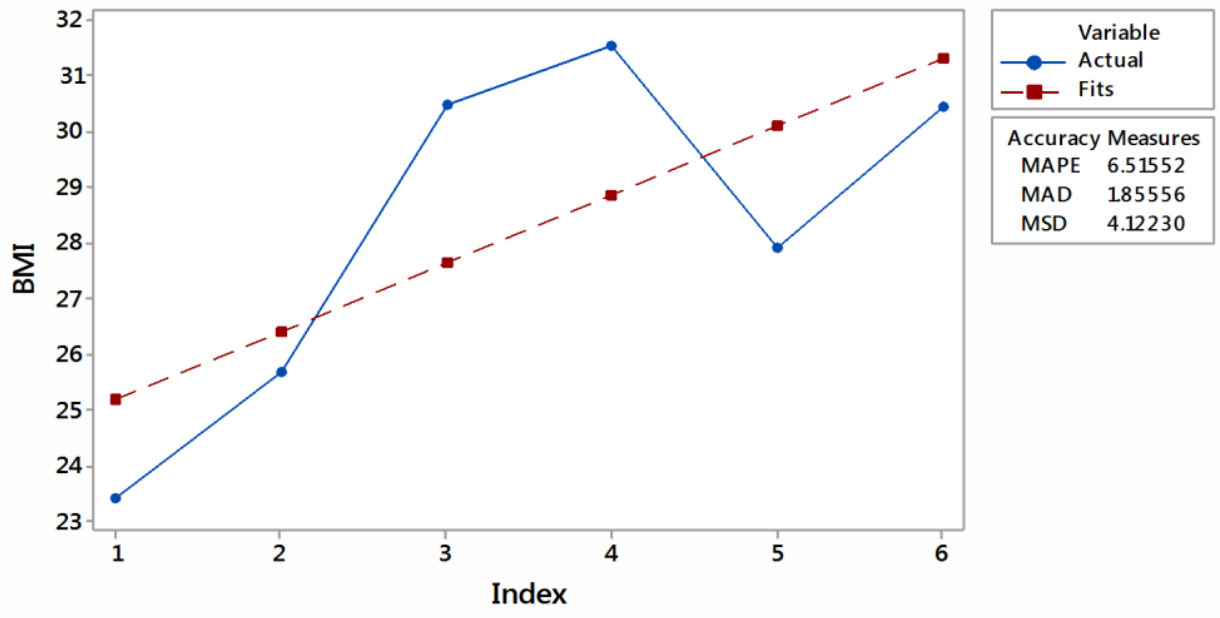

Fig. 4. trend analysis plot for Body mass index for the aged in Calabar South

Matrix Plot of BMI, Systole, Diastole, Weight, Height, Pulse rate, AGE

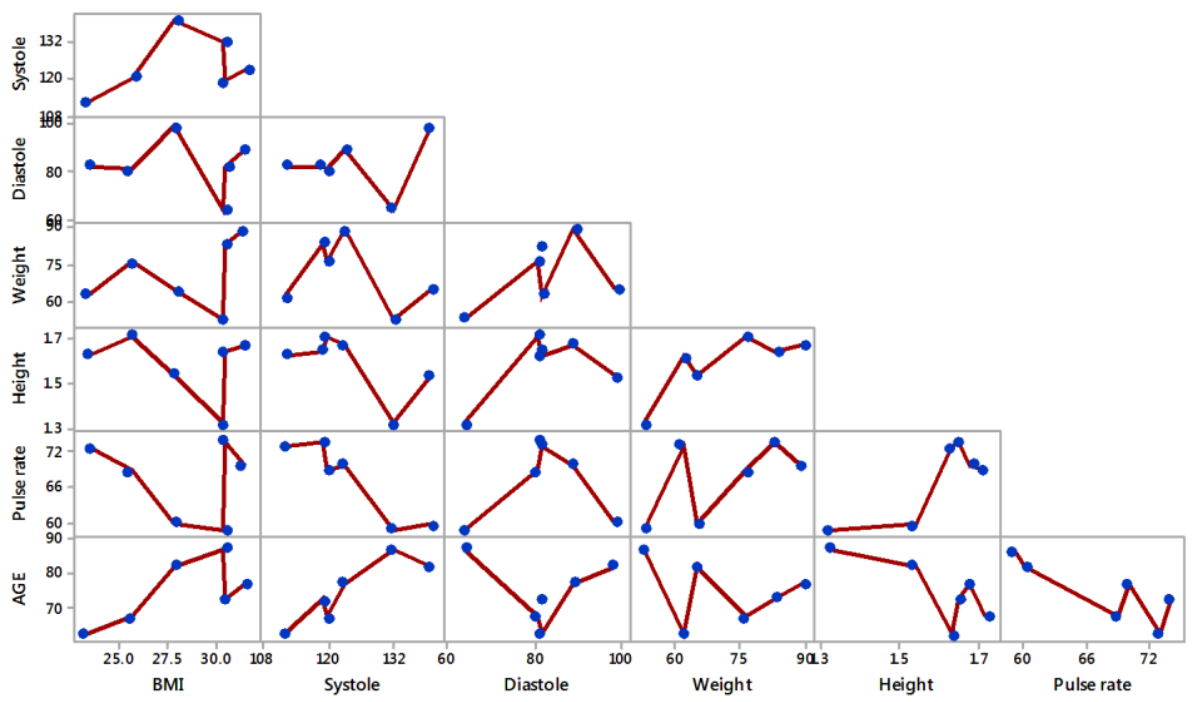

Fig. 5. Matrix plot of body mass index and blood pressure indicators 
Table 4. Item analysis of adjusted variables items of BMI and Blood pressure indicators

\begin{tabular}{|c|c|c|c|c|c|c|c|}
\hline Variable & Adj. total mean & Adj. total Std. dev. & Item -adj. total correlation & Squared multiple correlation & Cronbach's Alpha & Std. dev. & Age bracket \\
\hline BMI & 422.42 & 29.64 & 0.339 & 0 & 0.1716 & 3.20 & $61-65$ \\
\hline Systole & 326.51 & 24.14 & -0.1148 & 0 & 0.4401 & 9.75 & $66-70$ \\
\hline Diastole & 367.84 & 20.22 & 0.4010 & 0 & 0.1242 & 11.48 & $71-75$ \\
\hline Weight & 379.34 & 19.84 & 0.6762 & 0 & -0.0916 & 13.66 & $76-80$ \\
\hline Height & 449.08 & 26.44 & 0.1629 & 0 & 0.2833 & 0.15 & $81-85$ \\
\hline Pulse rate & 383.18 & 27.49 & -0.1439 & 0 & 0.4548 & 6.47 & $>85$ \\
\hline Age & 375.68 & 24.78 & -0.1310 & 0 & 0.4483 & & \\
\hline
\end{tabular}

NOTE * Cronbach's alpha and omitted-variable correlations calculated with standardized data.

Table 5. Comparative analysis of observation of BMI and BP test results amongst six age brackets for the aged in Calabar south (Turkey Pairwise Multiple Comparison Procedures Test)]

\begin{tabular}{|c|c|c|c|c|c|c|c|}
\hline \multicolumn{4}{|c|}{ BMI TEST } & \multicolumn{4}{|c|}{$\begin{array}{l}\text { BP TEST } \\
\end{array}$} \\
\hline Comparison & Diff of Ranks & $\mathbf{Q}$ & $P<0.05$ & Comparison & Diff of Ranks & $\mathbf{Q}$ & $P<0.05$ \\
\hline A2 vs A1 & 101.5 & 5.31 & No & A4 vs A6 & 252 & 3.98 & Yes \\
\hline $\mathrm{A} 2$ vs $\mathrm{A} 3$ & 184.2 & 3.74 & No & A4 vs A5 & 198.2 & 2.75 & No \\
\hline A2 vs $\mathrm{A} 4$ & 184.5 & 3.92 & Yes & A4 vs $\mathrm{A} 3$ & 134.8 & 2.55 & Yes \\
\hline $\mathrm{A} 2$ vs $\mathrm{A} 6$ & 132.3 & 3.946 & No & $\mathrm{A} 4$ vs $\mathrm{A} 2$ & 124.1 & 1.67 & No \\
\hline A2 vs $A 5$ & 502.5 & 2.05 & No & $\mathrm{A} 4 \mathrm{vs} \mathrm{A} 1$ & 301.3 & 1.54 & No \\
\hline $\mathrm{A} 5$ vs $\mathrm{A} 1$ & 199.3 & 5.26 & Yes & $A 1$ vs $A 6$ & 110.5 & 3.76 & Yes \\
\hline A5 vs $A 3$ & 281.1 & 2.91 & No & A1 vs A5 & 130.4 & 3.96 & No \\
\hline A5 vs $A 4$ & 108.2 & 2.64 & No & A1 vs $A 3$ & 176.5 & 2.44 & No \\
\hline A5 vs $A 6$ & 630.5 & 4.89 & Yes & $\mathrm{A} 1 \mathrm{vs} \mathrm{A} 2$ & 213.5 & 2.78 & No \\
\hline $\mathrm{A} 6$ vs $\mathrm{A} 1$ & 269.4 & 5.35 & Yes & $\mathrm{A} 2$ vs $\mathrm{A} 6$ & 197.2 & 2.45 & No \\
\hline$A 6$ vs $A 3$ & 151.1 & 1.68 & No & A2 vs $A 5$ & 137,8 & 1.95 & No \\
\hline A6 vs $A 4$ & 152.3 & 3.84 & No & $\mathrm{A} 2$ vs $\mathrm{A} 3$ & 113.5 & 1.15 & No \\
\hline A4 vs $\mathrm{A} 1$ & 211.7 & 4.22 & Yes & $A 3$ vs $A 6$ & 233.5 & 2.71 & No \\
\hline A4 vs A3 & 169.3 & 1.74 & No & $A 3$ vs $A 5$ & 173.5 & 1.81 & No \\
\hline $\mathrm{A} 3$ vs $\mathrm{A} 1$ & 117.4 & 3.67 & Yes & A5 vs $A 6$ & 660.6 & 4.82 & Yes \\
\hline
\end{tabular}




\section{DISCUSSION}

Guidance and genetic counseling and interventions will help tremendously in reducing exposures and risk factors of obesity associated with wide variety of common diseases of public health importance including hypertension, diabetes and obesity. The aged are experienced people with great wisdom who should continue to pass on their wealth of experience to the young ones for a better society. The early detection and identification of predisposing factors and subsequent treatment of early symptoms is possible to prevent, control and eliminate stress related diseases in among the aged in Calabar south will save life and reduce human mortality in the area and which have remained invaluable in public health assessment worldwide $[12,13]$.

The results revealed that all six age brackets evaluated for the aged showed 66- 70 and 81 -85 yrs showed pre -obese conditions while the other four age brackets showed obese class 1 hypertension respectively. The results further showed that five principal components accounted for 100 percent of total variations in BMI and BP for the aged in the study area with principal component one (PC1) with eigen value of 0.398 contributing $56.90 \%$ to the observed total variation. The principal loading variable for this component was obtained from pulse rate $(0.470)$. A trend linear model of $Y \mathrm{t}=23.94+1.233 \times \mathrm{t}$ was obtained for the trend analysis indicating the high dependence of the BMI and BP (Y) on age $(\mathrm{t})$. The results of Cronbach's alpha statistics revealed a high level of low precision and high standard errors among all variables evaluated showing less than 70 percent. The Turkey's multiple comparative analysis revealed high level of inconsistency among the variables as we compared one variable to another. This is in line with the reports of $[14,15]$.

Stress related disorder simply manifest in obesity, hypertension, stroke and other cardiac related ailments. Obesity is a health condition presented in the form of excessive fat in humans. It occurs when calories intake exceeds calories expended over an extended period of time. It some cases it is hereditary. Obesity is also the presence of large amount of fat in the subcutaneous tissues of the body. Mean values of body fat in the total body weight for normal young men is about $12 \%$ and for young women about $26 \%$ [16]. A man whose body fat amounts to over $20 \%$ of his total body weight may be considered obese and for women with figure of over $40 \%$ is an indication of obesity.
Obesity in this regards is multidimensional due to the high calorie intake which exceeds calorie expenditure (i.e over consumption or under expenditure of energy or frequently a combination of both). Over indulgence in sugary foods like cakes and chocolates and starchy foods like bread and biscuits as well as excessive or high intake of fatty foods $[17,18]$.

The risk factors of obesity include bad eating habits involving the continuous nibbling of food and abuse of alcohols and smoking. Physical activity and exercise - obesity is common with those people who live sedentary lifestyle like the aged than active individuals $[19,20]$.

Obesity has many health and social implications. Obesity predisposes individuals to diabetes, cancer, cardiovascular diseases, dental cares, etc. it may also lead to barrenness in females and hypertension in pregnant women. Life expectancy decreases by up to $25 \%$ in some cases. The social implication includes wearing of unfashionable clothes, shyness and job preferences as also reported by [20].

Preventive measures will entails calorie restriction, regular exercise, use of drugs e.g. appetite de-stimulatory drugs, and medical supervision [21]. Healthy diet with ample fibre, low in refined sugar, high in complex carbohydrates and moderate proteins are preventive measures. Others include regular exercise, weight reduction and refraining from habits like smoking and alcohol abuse which intake is very high and prevalent among the aged $[5,6,21]$.

\section{CONCLUSION}

The study had shown that the aged displayed exceptionally high blood pressure indices and body mass index which revealed pre-obese and obese class 1 for all the age brackets evaluated for the aged. These conditions of health status for the aged in the Calabar south also showed increasing stress related disorders among the aged. The linear trend model adopted in the study had revealed a high dependency of the body mass and blood pressure indices to rely heavily on increasing ages of the respondents. The Cronbach's Alpha analysis revealed very low precision and accuracy among the evaluated blood pressure and BMI variables for the aged. The Turkey's comparative model analysis for the $\mathrm{BMI}$ and blood pressure indices for the aged revealed a highly significant difference especially 
among the last age brackets evaluated. Hence, due to the increasing health risk associated with increasing body mass index with age, there is need to counsel the aged and seek for meaningful interventions for the aged from government, donor agencies, NGOs and wellmeaning individuals to intervene and reduced stress related disorders among the aged in Calabar South Local Government Area of Cross River State.

\subsection{Counselor Intervention Strategy}

i. Creation of awareness on the need for a regular and routine blood pressure check up for the aged by their caregivers.

ii. Create awareness on the potential risk factors that predisposes the aged to stress related disorders, like hypertension and obesity.

iii. Engage Government on the need to ensure prompt payment of retirement benefits and pensions to the aged retirees to reduce increasing blood pressure and stress related disorders arising from untold economic hardship for the aged retirees.

iv. The need for urgent guidance and counseling of the aged on the dangers of drug abuse, smoking and poor dieting which predisposes them to stress related disorders.

v. Advice government on the need for safety nets intervention program for the aged to forestall increasing cardiac associated disorders that is highly prevalence among the aged.

vi. Interact with Non-Governmental Organizations to assist in reaching out to the aged in the study area to reduce stress related disorders and heart diseases.

vii. Prevail on Donor agencies to strengthen and provide livelihood sources like conditional cash for the aged to reduce stress related disorders which predisposes them to high blood pressure.

\section{CONSENT}

As per international standard or university standard, respondents' written consent has been collected and preserved by the authors.

\section{COMPETING INTERESTS}

Authors have declared that no competing interests exist.

\section{REFERENCES}

1. Bulletin of Yale University. Epidemiology of Public health. $2003-2004 ; 30-31$.

2. Scott J. Molecular genetics of common diseases. In British Med. Journal. Basic molecular and cell biology: London: The BMJ Publication. 2003;71.

3. Peterson A. The new genetics and the politics of public health. Critical public health. 2000;8 (1): 59-65.

4. Ubi GM. Genetic Screening and Counselling: Implications for Public health as Tools for Interventions in Obesity and Diabetes. Interventions in Diabetes and Obesity. 2018;6(2):123 - 132.

5. Udiandeye FA, Effiom BE, Ubi GM. Correlation and Regression Analysis of Age and Body Mass Index (BMI) Among Nsidung Fisher Folks, Calabar South, Cross River State, Nigeria: The Counselor Sensitization Strategy. Annual Research and Review in Biology. 2021;6(2): 1- 12.

6. Bathje G, Pryor J. The relationship of public and self-stigma to seeking mental health services. Journal of Mental Health Counseling. 2011;33(2):161-176.

7. Studer G, Rempfer C, Waterhouse AM, Gumienny G, Haas J, Schwede T. QMEAN DisCo - distance constraints applied on model quality estimation. Bioinformatics. 2020;36:1765- 1771.

8. Bertoni M, Kiefer F, Biasini M, Bordoli L, Schwede T. Modeling protein quaternary structure of homo- and hetero-oligomers beyond binary interactions by homology. Scientific Reports 2017;7:12- 16.

9. Wu F, Zhao S, Yu B, Chen YM, Wang W, Zhang YL. A new coronavirus associated with human respiratory disease in China. Nature. 2020;579:265-269.

DOI:10.1038/s41586-020-2008-3 Medline

10. Zhou $P$, Yang XL, Wang XG, Hu B, Zhang $L$, Zhang W. A pneumonia outbreak associated with a new coronavirus of probable bat origin. Nature. 2020;579:270273.

DOI:10.1038/s41586-020-2012-7 Medline

11. Brown C, Conner KO, Copeland VC, Grote N, Beach S, Battista D, Reynolds CF. Depression stigma, race, and treatment seeking behavior and attitudes. Journal of Community Psychology. 2010;38:350-368.

12. Bruce N, Shapiro S, Constantino M, Manber R. Psychotherapists mindfulness and the psychotherapy process. 
Psychotherapy Theory, Research, Practice, Training. 2010;47(1):83- 97.

13. Calicchia J, Graham L. Assessing the relationship between spirituality, life stressors, and social resources: Buffers of stress in graduate students. North American Journal of Psychology. 2006;8:307-320.

14. Corrigan P. How stigma interferes with mental health care. American Psychologist. 2004;59 (7):614-625.

15. Corrigan PW, Watson AC, Barr L. The selfstigma of mental illness: Implications for self-esteem and self-efficacy. Journal of Social and Clinical Psychology. 2006;25 (9):875 -884.

16. Dearing $\mathrm{RL}$, Maddux JE, Tangney JP. Predictors of psychological help seeking in clinical and counseling psychology graduate students. Professional Psychology. Research and Practice. 2005;36(3):323-329.
17. Goldberstein E, Eisenberg D, Gollust S. Perceived stigma and mental health care seeking. Psychiatric Services. 2008; 59:392-399.

18. Holmes RP, Corrigan PW, Williams $\mathrm{P}$, Canar J, Kubiak MA. Changing attitudes about schizophrenia. Schizophrenia Bulletin. 1999;25:447-456.

19. Horsfall J, Cleary M, Hunt G. Stigma in mental health: Clients and professionals. Issues in Mental Health Nursing. 2010;31 :450-455.

20. Hugo M. Mental health professionals attitudes towards people who have experienced a mental health disorder. Journal of Psychiatric and Mental Health Nursing. 2001;8:419-425.

21. Martin J. Stigma and student mental health in higher-education. Higher Education Research \& Development. 2010; 29(3):259-274.

(c) 2021 Undiyaundeye et al.; This is an Open Access article distributed under the terms of the Creative Commons Attribution License (http://creativecommons.org/licenses/by/4.0), which permits unrestricted use, distribution, and reproduction in any medium, provided the original work is properly cited.

Peer-review history:

The peer review history for this paper can be accessed here: https://www.sdiarticle4.com/review-history/72215 